\title{
FORMAÇÃO CONTINUADA DE DOCENTES PARA AUTORIA BASEADA NO MODELO TPACK E NA ABORDAGEM CONSTRUCIONISTA, CONTEXTUALIZADA E SIGNIFICATIVA
}

\author{
CONTINUED TEACHER TRAINING FOR AUTHORSHIP BASED ON THE \\ TPACK MODEL AND CONSTRUCTIVE, CONTEXTUALIZED AND \\ SIGNIFICANT APPROACH
}

\author{
Mônia Daniela Dotta Martins Kanashiro ${ }^{1}$ \\ Klaus Schlünzen Junior ${ }^{2}$
}

\begin{abstract}
Resumo: Este estudo buscou analisar como docentes do Ensino Fundamental podem utilizar uma ferramenta de autoria em sua prática pautando-se na abordagem Construcionista, Contextualizada e Significativa, considerando os saberes do modelo TPACK, relativo a base de conhecimentos tecnológicos, pedagógicos e de conteúdos do professor. A pesquisa qualitativa do tipo investigação-ação, partiu da produção de um curso semipresencial aplicado a nove docentes. Os dados emergiram da observação de fóruns, materiais didáticos produzidos e questionário de autoavaliação. Observou-se a apropriação satisfatória da ferramenta de autoria por oito docentes; seis materiais criados incluíram a abordagem satisfatoriamente. Duas propostas não contemplaram conhecimentos pedagógicos do modelo TPACK. Evidenciou-se a importância da centralidade do estudante no processo de planejamento da prática e observou-se que a abordagem Construcionista, Contextualizada e Significativa tem potencial para promover a aprendizagem conforme o modelo TPACK, porém este carece de considerar a abordagem para que a integração dos seus saberes se realize plenamente.
\end{abstract}

Palavras-chave: Formação Docente; Anos Iniciais do Ensino Fundamental; TPACK; Abordagem CCS; Tecnologias na educação.

\begin{abstract}
This study sought to analyze how elementary school teachers can use an authoring tool in practices based on the Constructionist, Contextualized and Significant approach, considering the knowledge of the TPACK model, related to the technological, pedagogical and teacher knowledge base. The action-research qualitative, started from the production of a semi-presential course applied to nine teachers. The data emerged from the observation of forums, educational materials and a self-assessment questionnaire. There was a satisfactory appropriation of the authoring tool by eight teachers; six materials created included the approach satisfactorily. Two proposals didn't include pedagogical knowledge of the TPACK model. The importance of the student's centrality in the practice planning process was evidenced and it was observed that the Constructionist, Contextualized and Significant approach has the potential to promote learning according to the TPACK model, however, he needs to consider the approach so that the integration of his knowledge is fully realized.
\end{abstract}

Keywords: Teacher Education; Early Years of Elementary School; TPACK; CCS approach; Technologies in education.

\footnotetext{
${ }^{1}$ Mestra em Educação, Universidade Estadual Paulista - UNESP. Gestora de projetos pedagógicos na Multimídia Educacional, Presidente Prudente, São Paulo, Brasil. E-mail: daniela.martins@multimidiaeducacional.com.br

${ }^{2}$ Professor livre-docente em Informática e Educação pela Universidade Estadual Paulista - UNESP, professor do Departamento de Estatística e do programa de Pós-graduação em Educação da FCT/UNESP, Presidente Prudente, São Paulo, Brasil. E-mail: klaus.junior@unesp.br
} 


\section{Introdução}

No Brasil, o acesso à educação básica vem avançando ao longo do tempo em uma ampliação gradual e contínua. "A cobertura no ensino fundamental de nove anos chegou, em 2019, a 98\% das crianças e adolescentes de 6 a 14 anos na escola, tendo praticamente sido universalizada" (BRASIL, 2020, p.13). No entanto, a preocupação maior em relação à educação brasileira continua sendo o baixo nível de aprendizado dos alunos. No ciclo da alfabetização, os resultados da Avaliação Nacional da Alfabetização (ANA) de 2016 mostravam que, na área da Leitura, mais de $20 \%$ dos alunos do $3^{\circ}$ ano do ensino fundamental das instituições públicas só atingiram o nível mais baixo da escala (nível 1) e por volta de 50\% deles nem chegaram a avançar do nível 2 (BRASIL, 2020).

Tal contexto parece refletir uma desmotivação dos estudantes para com os conteúdos escolares, uma vez que o sistema educacional historicamente é marcado por práticas que pouco estimulam a participação ativa do estudante em sua aprendizagem. Nesse sentido, Veen e Vrakking (2009, p.47) apontam que as crianças que nasceram imersas na tecnologia "consideram a escola um lugar monótono, para elas o conteúdo ensinado na escola em si é irrelevante para suas vidas". Ademais, com a evolução das tecnologias e da internet, vivemos num momento no qual elas permitem o acesso ao conhecimento em qualquer hora e lugar, e as aprendizagens ultrapassam os muros da escola, ocorrendo em qualquer ambiente por meio dos mais diversos canais (COLL; MONEREO, 2010; LIBÂNEO, 2010). Nessa nova realidade social, são revelados novos comportamentos de interação e aprendizagem com participação do indivíduo cada vez mais ativa, o que a escola, por sua vez, ainda não favorece.

Assim, é inegável que a escola precisa se renovar para acompanhar as transformações sociais e não perder sua relevância, porquanto, segundo Coll e Monereo (2010), ela ainda é a única instituição que pode promover a apropriação da cultura às novas gerações em condições confiáveis e significativas. E nesse processo, o professor tem papel fundamental, pois é a partir de sua intervenção que a educação formal se realiza. Por isso, é preciso que ele se distancie do papel de técnico que transmite informações e torne-se um mediador na construção dos conhecimentos pelos estudantes, utilizando o potencial das ferramentas tecnológicas para promover o engajamento e participação dos estudantes em sua aprendizagem.

Todavia, estruturar as escolas com equipamentos modernos, softwares, internet e oferecer formações técnicas aos docentes não é garantia de melhoria à Educação. Segundo 
Venezky e Davis (2002 apud COLL; MONEREO, 2010, p. 33), estudos têm evidenciado que experiências satisfatórias com a inserção das Tecnologias Digitais da Informação e Comunicação (TDIC) em determinadas instituições acabam não tendo o mesmo êxito obtido em outras e que, por vezes, escolas equipadas com últimas inovações em ferramentas tecnológicas, softwares e infraestrutura, frequentemente desenvolvem práticas educacionais de nível baixo. Além disso, segundo o Comitê Gestor da Internet do Brasil, é possível observar que "dentro do contexto educacional, o aproveitamento das TIC já é observado, mas ainda é bastante centrado em atividades instrumentais, como pesquisa e busca por informação" (CGI, 2017, p. 111), sem desenvolver nos professores e estudantes uma construção ativa do saber. O que demonstra que não é apenas o plano material que requer mudanças, mas urge a necessidade de renovar as práticas docentes em sentido amplo, passando de uma visão transmissivista para uma visão autoral, criativa e contextualizada que crie significados aos conteúdos desenvolvidos, aproveitando toda a riqueza dos recursos tecnológicos para promover reflexão e aprendizagem de forma dialógica, caminho este que exige do docente reflexão constante e desenvolvimento de sua autonomia.

Tal transformação depende de mudanças nos processos formativos que deveriam acompanhar as inovações na sociedade, começando dos cursos de licenciatura e se estendendo em formações continuadas durante toda trajetória do professor. Todavia, o que se tem visto são cursos de licenciatura com forte tradição disciplinar e uma fragmentação formativa que não favorece a inovação, o pensamento criativo e a reflexão do contexto amplo. Para Gatti (2010, p. 1375), “é necessária uma verdadeira revolução nas estruturas institucionais formativas e nos currículos da formação [...]", segundo a autora, "a formação de professores profissionais para a educação básica tem que partir de seu campo de prática e agregar a este os conhecimentos necessários selecionados como valorosos [...]" (GATTI, 2010, p. 1375), o que, mediante o contexto atual, deve também considerar o uso das mídias e tecnologias. No que se refere à formação continuada para uso das tecnologias na educação, o cenário não é diferente, pois ainda predominam programas de formação com foco em habilidades técnicas, descontextualizados da realidade vivenciada na prática. Silva (2014) aponta que os cursos de formação continuada ainda não dão conta de formar o professor para o uso das tecnologias no seu dia a dia de trabalho. Além disso, segundo a autora, há contextos em que as formações continuadas são obrigatórias, revelando a desmotivação dos docentes em participar de cursos que não atendem suas expectativas. 
Sobre os saberes necessários para que o professor integre a tecnologia em suas práticas, Mishra e Koehler (2006), baseando-se em estudos de Shulman (1986), afirmam que os docentes precisam articular três tipos de conhecimentos para obterem sucesso em sua prática de ensino: o Conhecimento do Conteúdo, do inglês Content Knowledge $(C K)$, que se refere aos conceitos do que pretende ensinar; o Conhecimento Pedagógico, do inglês Pedagogical Knowledge $(P K)$, aquele que se debruça sobre a didática e os métodos de ensino do professor; e o Conhecimento Tecnológico, do inglês Technological Knowledge (TK), o qual se refere ao saber docente no uso da tecnologia, não sendo o saber técnico apenas, mas compreensão do potencial educacional dos recursos tecnológicos, saberes esses que devem se encontrar e se integrar numa intersecção, chamada pelos autores de Base de Conhecimentos Tecnológicos Pedagógicos de Conteúdos, do inglês Technological Pedagogical Content Knowledge (TPACK) ou modelo TPACK, que diz respeito aos conhecimentos tecnológicos, pedagógicos e do conteúdo, que devem estar integrados e relacionados na prática educativa do professor; e que precisam ainda ser desenvolvidos em uma formação ampla, integrada e contextualizada, distante do que se vê atualmente nas práticas formativas, por vezes fragmentadas e descontextualizadas das reais demandas da escola.

Nesse contexto, a abordagem Construcionista, Contextualizada e Significativa (CCS), desenvolvida por Schlünzen (2000, 2015), apresenta uma nova forma de contato com os assuntos escolares e tem potencial para contribuir com a prática do professor para o uso da tecnologia, uma vez que possibilita uma conexão de conteúdos de modo interdisciplinar e motivador de desenvolver a prática pedagógica com os estudantes, que podem ter resultados de sucesso a partir da articulação por meio de projetos. Nela, os anseios dos estudantes são considerados, bem como seus saberes prévios valorizados e a tecnologia é parte do processo, sendo utilizada como ferramenta para a construção do conhecimento através da criação de um produto palpável em que se sistematize e se consolide a aprendizagem dos conceitos dos conteúdos trabalhados.

O caminho para a mudança vai ao encontro de uma atuação mais autônoma do professor, que deve ter liberdade de atuação cumprindo as demandas escolares de sua responsabilidade, mas também considerando as motivações de seus estudantes e seus próprios anseios profissionais, refletindo sobre seu trabalho e complementando os materiais didáticos já utilizados na escola com produções autorais suas e de seus aprendizes em uma proposta de interação educacional mais prazerosa. 
Por isso, visando refletir sobre contribuições para a melhoria da educação mediante o contexto atual, desenvolveu-se esta pesquisa, que foi formatada a partir de uma de formação interventiva semipresencial com o propósito de possibilitar uma mudança na prática docente com o uso da tecnologia.

O objetivo principal da pesquisa foi investigar como os docentes dos anos iniciais do Ensino Fundamental poderiam utilizar uma ferramenta de autoria online para que desenvolvessem uma prática pedagógica pautada na abordagem CCS e que considerasse o modelo da base de conhecimentos TPACK. Para isso, buscou-se atender aos seguintes objetivos específicos:

- Identificar as competências necessárias para a construção de materiais didáticos a partir de uma ferramenta de autoria online e à luz do modelo TPACK;

- Verificar como desenvolver um processo formativo, a partir de uma proposta de um curso, que permita ao docente compreender os princípios da abordagem CCS na utilização de uma ferramenta de autoria online para produzir seus materiais didáticos;

- Analisar os materiais didáticos e planos de aprendizagem construídos a fim de identificar de que forma contemplam a abordagem CCS e a apropriação da ferramenta tecnológica de autoria pelos docentes participantes segundo o modelo TPACK.

Partiu-se então para os estudos teóricos sobre formação continuada de professores no uso das tecnologias, as competências docentes para desenvolvimento do modelo TPACK e os princípios da abordagem CCS, estudos que nortearam a construção de uma formação semipresencial desenvolvida exclusivamente para esta pesquisa e que serão apresentados nas seções seguintes.

\section{Formação continuada de professores e as TDIC}

Considerando a evolução da prática docente ao longo da história da educação, a atividade educacional foi considerada inicialmente como uma arte durante muito tempo; em seguida, nos tempos modernos, passou a ser considerada uma técnica e, mais recentemente, uma interação (TARDIF, 2002). Ao longo desse processo de transformação, os conhecimentos docentes, o saber-fazer, as competências e as habilidades que os professores mobilizam em seu trabalho também se modificaram e uma 
nova mudança agora se mostra necessária: a integração da tecnologia ao processo educativo. Uma vez que, nos tempos atuais, a forma de pensar, agir e se comportar da sociedade se modificou em razão do desenvolvimento tecnológico, e no contexto atual, como aponta Moran (2004), a criança também é educada pela mídia, aprendendo a informar-se, a conhecer o mundo, vendo e ouvindo pessoas na tela que lhe mostram como viver, ser feliz e infeliz, amar e odiar, aprendendo novas formas de pensar e de sentir.

Para Moran, “[...] o avanço do mundo digital traz inúmeras possibilidades, ao mesmo tempo em que deixa perplexas as instituições sobre o que manter, o que alterar, o que adotar” (MORAN, 2004, p. 11). Segundo o autor, “[...] sem planejamento adequado, as tecnologias dispersam, distraem e podem prejudicar os resultados esperados" (MORAN, 2004, p. 59), ou seja, sem a adequada mediação docente as tecnologias podem favorecer apenas o entretenimento e não o conhecimento. E neste cenário, o papel fundamental do professor na educação escolar é ser o mediador interessante, competente e confiável entre o que a escola propõe em cada nível e o que os estudantes esperam, desejam e realizam (MORAN, 2004).

Libâneo (2010) afirma que, nessa escola emergente, os professores devem estar preparados às novas exigências, além de ter sólida cultura geral, precisam desenvolver sua capacidade de aprender a aprender, saber comunicar-se de diversas formas, ter domínio da linguagem informacional e saber articular as aulas com as mídias e multimídias.

Em consonância com tais ideias, Andrade (2003) aponta que o uso da tecnologia na educação

[...] requer novas estratégias, metodologias e atitudes que superem o trabalho educativo tradicional ou mecânico [...] as novas características são de uma escola aprendente, mediadora da construção do conhecimento dos seus beneficiários e orientadora do desenvolvimento cognitivo, emocional, estruturadora do pensamento, das capacidades e competências de aprender a aprender (ANDRADE, 2003, p. 58).

Neste contexto, as ferramentas de autoria mostram-se fortes aliadas para que os docentes sejam incluídos digitalmente e busquem renovação em suas práticas, integrando em seu cotidiano o potencial da tecnologia, que tanto seduz as crianças, e sua reflexão e capacidade criativa frente aos desafios que encontra em sua ação pedagógica. Segundo Leffa (2006), “[...] uma Ferramenta de Autoria é um programa de computador usado para a produção de arquivos digitais, geralmente incluindo texto escrito, imagem, som e vídeo" (LEFFA, 2006, p. 190). Em geral, fáceis de manipular, tais ferramentas permitem que os 
professores criem materiais ou incorporem em suas produções, mídias já criadas e disponíveis na web.

Todavia, tornar-se um professor autor não é tarefa fácil. Bispo (2015) afirma que,

[...] tornar-se um professor pesquisador é a base para que o docente se torne também um professor autor, capaz de, por meio do uso das novas tecnologias de informação e comunicação, propiciar ao aluno um ambiente em que ele também se torne autor do seu próprio conhecimento (BISPO, 2015, p.1).

Segundo a autora, a pesquisa favorece a formação da consciência crítica que parte do exercício do questionamento e por isso, precisa constituir-se como atividade cotidiana dos professores. Porém, para que o professor exerça tal papel, é preciso investir em sua formação inicial e continuada, formação essa que se dá durante todo o caminho profissional do docente, dentro e fora da sala (KENSKI, 2003). A formação continuada dos professores não pode ser meramente baseada no currículo escolar, mas precisa considerar o contexto e as transformações vivenciadas, sobretudo, as trazidas pela inserção das tecnologias no cotidiano, refletindo inclusive sobre a responsabilidade do professor no trabalho com elas, uma vez que as informações advindas das tecnologias podem estar carregadas de ideologias. Por isso, Kenski (2003) aponta para a necessidade de que o professor tenha tempo e oportunidade de familiarizar-se com novas tecnologias educativas, suas possibilidades e limites, para que tenha autonomia e faça escolhas conscientes no uso dos recursos.

No entanto, o que se tem visto em relação à formação continuada dos professores é que as ações nos momentos de formação e planejamento raramente levam em consideração o novo cenário social e, quando incluem tecnologia na pauta, o objetivo é voltado para a inclusão digital técnica e não se amplia para o desenvolvimento de competências frente às TDIC e à reflexão sobre seu potencial. Percebe-se, assim, que

O aparelhamento de escolas com tecnologias digitais, seguido de cursos voltados para "o uso de...", parece não estar sendo orientado a partir da perspectiva de professores autores, mas sim consumidores - de apostilas, de websites, de planos de ensino on-line, roteiros e instruções programadas, softwares para o reforço e a memorização etc (LOPES; SOMMER; SCHMIDT, 2014, p.59)

Segundo Gatti (2010, p. 1374), nos cursos de licenciatura em Pedagogia, os "Saberes relacionados às tecnologias no ensino estão praticamente ausentes." Lopes e Furkotter (2016, p. 274) afirmam que, "não basta incorporar as tecnologias à formação inicial, é preciso ressignificá-las" de modo que o professor seja formado para aplicação da tecnologia em situações práticas. 
Quanto à formação continuada, Silva (2014, p. 15) aponta que, "as formações ainda não estão sendo suficientes para garantir a autonomia do professor em utilizar essas tecnologias no seu cotidiano profissional”. Formar professores para uso das TDIC não consiste apenas em promover proficiência no uso das tecnologias, é preciso, antes, oferecer novas concepções de ensino e aprendizagem que extrapolem a visão tradicional do processo educativo. Imbernón (2010) acrescenta que, "os professores precisam ser os protagonistas ativos de sua formação em seu contexto de trabalho, no qual as decisões entre o prescrito e o real devem combinar [...]" (IMBERNÓN, 2010, p. 41), para o autor, a formação continuada deve promover mais do que atualização, deve ser capaz de criar espaços de formação, de pesquisa, de inovação e, sobretudo, de imaginação, favorecendo o desenvolvimento da autoestima docente. Deste modo, e para além da proficiência nas ferramentas, o docente precisa ampliar seu olhar para o papel do estudante na construção do saber, tendo clara para si a finalidade específica que espera do processo educativo com o uso da tecnologia e saber não apenas qual ferramentas usar, mas, por que e como usar.

\section{A base de conhecimentos do modelo TPACK}

Para obter resultados eficazes no processo educativo, o professor precisa agregar diferentes tipos de saberes. Assim, a base de conhecimentos do modelo TPACK (Technological Pedagogical Content Knowledge), definida por Mishra e Koehler ( 2006), diz respeito aos conhecimentos tecnológicos, pedagógicos e do conteúdo que devem estar integrados e relacionados na prática educativa do professor, que, além do domínio dos conceitos e conteúdos a serem trabalhados e da sua competência para articular os saberes com o contexto real, precisa ter domínio do saber tecnológico, ou seja, conhecer e saber utilizar as ferramentas que mais são adequadas a cada contexto e conteúdo a ser desenvolvido, é o que afirmam os autores Mishra e Koehler (2006).

Esses autores, fundamentando-se em Shulman (1986), afirmam que ao longo do tempo, a formação dos professores tinha como foco o conhecimento do conteúdo (do inglês Content Knowledge - $C K$ ), ou seja, o saber referente ao conteúdo o qual se desejava ensinar aos estudantes. Posteriormente, passou-se a valorizar nas formações docentes as formas de ensinar, as didáticas ou métodos de ensino, o que ele chamou de conhecimento pedagógico (do inglês Pedagogical Knowledge - PK); tendo este último, seu foco de atenção nas práticas da sala de aula. No entanto, essa valorização surgiu fragmentada dos conhecimentos de conteúdos $(C K)$. Assim, a formação de professores passou a enfatizar 
ora o conhecimento pedagógico $(P K)$, ora o conhecimento de conteúdo $(C K)$, não articulando esses dois saberes na formação docente (MISHRA; KOEHLER, 2006).

Shulman (1986, apud MISHRA; KOEHLER, 2006, p.1021) então, propôs a intersecção entre esses saberes, resultando no Conhecimento Pedagógico do Conteúdo (do inglês Pedagogical Content Knowledge - PCK), essa junção representa a situação pedagógica na qual o professor conhece e tem domínio do conteúdo a ser desenvolvido e volta seu olhar para como seus estudantes aprendem, para então, realizar abordagens e estratégias pedagógicas visando tornar o assunto acessível a eles.

A partir daí, os autores Mishra e Koehler (2006) defendem que, a essa intersecção $(P C K)$, deve ser integrado também o Conhecimento Tecnológico (do inglês Technological Knowledge -TK), que relaciona-se ao saber do professor no uso da tecnologia, não sendo meramente o saber técnico, mas também a compreensão ampla do potencial produtivo da tecnologia a ser utilizada no mundo e no cotidiano, reconhecendo suas possibilidades e limites para aplicação nas ações educativas (KOEHLER; MISHRA; CAIN, 2015), entendendo, pois, como tecnologia, nesse contexto, as ferramentas e técnicas inseridas em determinado momento histórico e que vão se transformando assim como a sociedade (KENSKI, 2003), tais como: livros, giz lousa, e também as mais avançadas - como internet, softwares, vídeo, dentre outros.

Com tal intersecção, surgem novas inter-relações entre conteúdo, pedagogia e tecnologia, cuja convergência central resulta no Conhecimento Tecnológico Pedagógico do Conteúdo (do inglês Technological Pedagogical Content Knowledge - TPCK) (MISHRA; KOEHLER, 2006), que integra os saberes das três áreas: tecnologia, pedagogia e conceitos de conteúdo; nascia então, a base de conhecimentos TPACK, cuja letra "A", inserida na sigla posteriormente, trazia justamente a ideia de pacote, uma vez que que os três domínios de conhecimento (tecnologia, pedagogia e conteúdo) não devem ser vistos de forma isolada, mas sim concebidos de forma integrada e interdependente em relação às três categorias de conhecimentos que o compõem e "uma alteração em qualquer uma das categorias deve ser compensada por mudanças nas outras duas (MISHRA; KOEHLER, 2006 apud SOUSA; TERÇARIOL; GITAHY, 2017, p. 1221).

Assim, o TPACK, cujo diagrama da Figura 1 ilustra, não pode ser colocado em prática por especialistas em um conteúdo e com habilidades tecnológicas apenas, ou por técnicos que conhecem pouco do conteúdo ou da pedagogia, ou ainda por professores que sabem pouco do conteúdo ou pouco da tecnologia (MISHRA; KOEHLER, 2006 apud SOUSA; TERÇARIOL; GITAHY, 2017, p. 1221). 
Figura 1: Intersecção proposta por Mishra e Koehler (2006), integrando os conhecimentos pedagógicos $(P K)$, de conteúdos $(C K)$ e tecnológicos $(T K)$, gerando o $T P A C K$

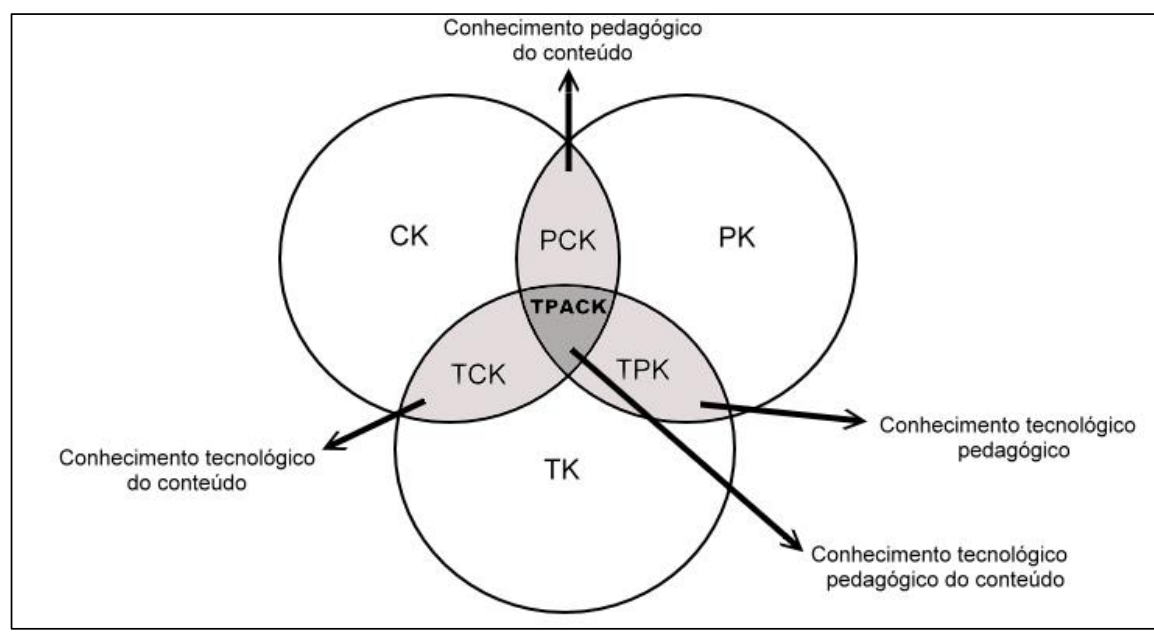

Fonte: Elaborado pelo autor com base em Mishra e Koehler (2006)

Como observado, o TPACK é o centro das relações entre os conhecimentos necessários à docência, representa a intersecção entre o saber do conteúdo $(C K)$, o saber pedagógico $(P K)$ e o saber tecnológico $(T K)$ e requer compreensão da relação de conceitos com estratégias pedagógicas que utilizem a tecnologia de maneira adequada para a construção da aprendizagem (KOEHLER; MISHRA; CAIN, 2015).

Ressalta-se pois, que desenvolver no professor essa base de conhecimentos que engloba diferentes saberes e competências formando o TPACK, é tarefa complexa e exige formação inicial e continuada, de modo que não apenas se ensine e exemplifique aplicações bem-sucedidas, mas também se promova reflexão e experimentação, uma vez que o TPACK, quando "aliado a uma metodologia ativa, favorece a aquisição de conhecimentos conceituais atrelados aos conhecimentos procedimentais inerentes à atuação docente" (SOUSA; TERÇARIOL; GITAHY, 2017, p. 1235).

Mediante o contexto apresentado, pensando sobre como formar o professor; quais saberes são necessários para que este desenvolva uma prática que esteja em consonância com as ideias até aqui apresentadas e que favoreça desenvolver, a partir de sua própria vivência e reflexão, maneiras de planejar, criar e realizar que atendam seus anseios e as demandas de seus estudantes em uma aprendizagem significativa, a seção seguinte versará sobre os princípios da abordagem CCS (SCHLÜNZEN, 2000, 2015), que, por suas contribuições, mostrou-se promissora para integrar ensino e tecnologia em uma educação de qualidade para todos. 


\section{A abordagem CCS e o Ensino Fundamental}

Nos cinco anos iniciais do Ensino Fundamental, as crianças desenvolvem conhecimentos que serão essenciais para toda sua trajetória educacional e, em relação a esse aspecto, a Base Nacional Comum Curricular (BNCC) destaca que, "as características dessa faixa etária demandam um trabalho no ambiente escolar que se organize em torno dos interesses manifestos pelas crianças, de suas vivências mais imediatas [...]" (BRASIL, 2017, p. 53). O documento afirma ainda que, "as experiências das crianças em seu contexto familiar, social e cultural, [...] e sua interação com as mais diversas tecnologias de informação e comunicação são fontes que estimulam sua curiosidade" (BRASIL, 2017, p. 53).

Nesse sentido, em consonância com o que estabelece a BNCC, a abordagem CCS (SCHLÜNZEN, 2000, 2015) pressupõe que, a aprendizagem acontece quando o conteúdo desenvolvido é contextualizado segundo a realidade e os desejos do aprendiz, atribuindo significados para informações que transformam-se em conhecimentos. Nessa abordagem, a tecnologia é empregada como ferramenta para a construção do saber a partir de produções do próprio estudante, articulando vivências, desejos, conceitos e currículo de forma contextualizada e significativa a partir da mediação do professor.

Assim, o enfoque 'construcionista' da abordagem CCS, diz respeito ao uso dos recursos de tecnologia que são empregados na resolução de problemas apresentados ou elaborados pelos próprios estudantes, utilizando a tecnologia e organizando seu pensamento para produzir algo do seu interesse, e segundo Schlünzen (2015),

[...] essa construção dá-se de maneira que o uso de tecnologias altera as estruturas do pensamento (mentais), por meio da interação do estudante com os mais diversos recursos, proporcionando uma reflexão constante com o papel de depurar os processos de constituição de tal interação (SCHLÜNZEN, 2015, p.73-74).

É preciso mencionar que, conforme afirma Schlünzen (2000), o termo "construcionismo" teve suas origens a partir do trabalho pioneiro de Seymour Papert (1985) com a implementação da linguagem de programação Logo. Sobre isto, Schlünzen, (2000), afirma que a abordagem Construcionista "consiste em criar situações que permitem ao aluno resolver problemas reais e aprender com o uso e com a experiência, com os conceitos envolvidos no problema que está sendo resolvido" (SCHLÜNZEN, 2000, p. 76). Nesta abordagem, o computador “[...] deixa de ser um meio de transferir informação e passa a ser uma ferramenta pela qual o aluno pode construir os seus conhecimentos, testar suas hipóteses e suas estratégias”, a partir de ações concretas por 
ele realizadas na construção de um produto palpável que lhe satisfaça (SCHLÜNZEN, 2000 p. 77), ou seja, a abordagem dá lugar à atuação ativa do estudante em sua aprendizagem.

Já o caráter 'contextualizado' da abordagem CCS, se refere à personalização do processo educativo, que parte das vivências e da realidade do aprendiz, para produzir novos saberes, pois todo conhecimento precisa estar relacionado com seu contexto para que seja significativo (SCHLÜNZEN, 2015).

Enquanto a dimensão 'significativa' da abordagem, diz respeito à importância dada aos anseios e desejos dos estudantes em seu processo de aprendizagem e em como ele busca dar sentido ao que está aprendendo. Nessa dimensão, a abordagem CCS possibilita que o interesse e autonomia do estudante sejam estimulados, gerando motivação, participação ativa, colaboração e a aprendizagem significativa do que está sendo trabalhado na mediação pedagógica (SCHLÜNZEN, 2015). A aprendizagem significativa a que se refere à abordagem CCS, parece convergir com a teoria da Aprendizagem Significativa de David Ausubel (1968), referenciada por Moreira (2006), a partir da qual a conexão dos novos conteúdos com os conhecimentos prévios do estudante, por ele nomeados de subsunçores, são fundamentais no processo de aprendizagem. De acordo com Moreira (2006), a aprendizagem significativa acontece a partir da “[...] interação entre o novo conhecimento e o conhecimento prévio. Nesse processo, o novo conhecimento adquire significados para o aprendiz e o conhecimento prévio fica mais rico" (MOREIRA, 2006, p. 17). Segundo a teoria da Aprendizagem Significativa de Ausubel, o conhecimento prévio é o elemento de maior influência na aprendizagem, visto que, só podemos aprender a partir do que já conhecemos (MOREIRA, 2006).

Segundo Santos e Schlünzen (2015, p. 937), “a abordagem CCS é fundamentada em três teorias: piagetiana, vigotskiana e freireana", trazendo, em sua proposta, as contribuições do cognitivismo, interacionismo e humanismo, ou seja, da descoberta a partir da ação sobre o objeto de estudo e da interação com os pares e com o meio, além do aproveitamento dos níveis de desenvolvimento mental real e potencial (com a ajuda do outro, no caso colegas e professor mediador), visando uma ação transformadora, consciente e crítica, demonstrando que o aprendiz é capaz de agir diante de uma situação ou problema, e aprender com a experiência e os conceitos envolvidos, afastando-se da "educação bancária", mencionada por Paulo Freire, em que as informações 
descontextualizadas são depositadas nas mentes dos estudantes (SANTOS; SCHLÜNZEN, 2015).

Para Schlünzen (2000, 2015), no processo educativo, é necessário valorizar a diversidade humana, assim como é preciso que o professor tenha sensibilidade e percepção das necessidades de ampliação dos conhecimentos a serem construídos pelos seus aprendizes e organize ações didáticas que levem os estudantes a refletir e conhecer novos conceitos, sem deixar de considerar que cada indivíduo tem seu próprio caminho de construção do conhecimento.

No entanto, para que o professor desenvolva tal abordagem em sua prática e alcance resultados de sucesso, é preciso que, em sua própria formação, ele vivencie essa construção. Nesse sentido, a perspectiva de uma formação de professores construcionista, contextualizada e significativa prevê que o professor seja formado não apenas para usar a tecnologia, mas para que também aprenda com ela e consiga sistematizar suas reflexões a partir dos recursos que ela oferece, de modo que analise suas demandas profissionais e pessoais, considere o interesse e o potencial de seus estudantes e as reações destes frente às ações pedagógicas, compartilhe experiências e aplique a tecnologia em seu contexto transformando-o positivamente, estabelecendo uma relação entre a vida real de seus aprendizes com os conceitos pedagógicos ensinados (SCHLÜNZEN; SCHLÜNZEN; SANTOS, 2011).

Pode-se entender que, formar o professor para autoria com o uso de tecnologias em sua prática, favorece a adoção de estratégias para a contextualização do ensino às suas reais demandas. No entanto, é preciso formar o docente para que se torne um profissional reflexivo, consciente das transformações que a sociedade vive, ciente do contexto em que atua e conhecedor das realidades e anseios dos estudantes (SCHLÜNZEN; SANTOS, 2016).

Assim, considerando a base de conhecimentos do modelo TPACK, já apresentada anteriormente, é possível vislumbrar na Abordagem CCS, uma possibilidade promissora para o aproveitamento das TDIC como apoio na construção do conhecimento pelos estudantes, uma vez que ela situa o aprendiz como protagonista do seu processo de aprendizagem.

\section{Etapa empírica e metodologia da pesquisa}

O universo da pesquisa, contou com um grupo de nove docentes participantes que 
atuavam nos anos iniciais do Ensino Eundamental em redes públicas municipais do interior de São Paulo, docentes estes, com conhecimentos básicos de tecnologia, como saber navegar na web e usar editores de texto. Com tais participantes foi realizada uma formação semipresencial de abril a junho de 2019, tendo como ferramenta uma plataforma Moodle como ambiente virtual de aprendizagem, acessado a partir do site www.cpides.com.br, e a pesquisadora responsável por este estudo como desenvolvedora dos conteúdos, observadora e tutora da turma durante a realização do curso. Para tanto, foram realizados dois encontros presenciais, um no início, para apresentação da formação, e um no final, para autoavaliação do processo, além de cinco tópicos a distância que ocorreram online, buscando apresentar às participantes os princípios da abordagem CCS (SCHLÜNZEN, 2000, 2015) e promover-lhes o desenvolvimento de competências segundo o modelo TPACK (MISHRA; KOEHLER, 2006), com vistas a uma prática baseada na mediação integrando, conhecimentos de conteúdo, pedagógicos e tecnológicos de forma harmônica e que culminassem na criação de um plano de aprendizagem e na produção de materiais digitais de apoio que sustentassem a prática pedagógica planejada.

Assim, este estudo é de natureza qualitativa, uma vez que, de acordo com Bogdan e Biklen (1994), nesse tipo de investigação, o pesquisador está em contato direto com o ambiente e as situações a serem investigadas, havendo interesse em descrever e analisar o processo e não simplesmente os resultados. Já como tipologia metodológica, esta pesquisa configurou-se como uma investigação-ação, que, no campo da educação, “[...] é utilizada principalmente como uma forma de desenvolvimento profissional" (ANDERSON; HERR, 2016, p.5), envolvendo planejamento e intervenções do pesquisador junto à participação ativa dos envolvidos, com vistas a produzir melhorias na prática pedagógica dos participantes, e buscando "gerar conhecimentos a partir das ações ou intervenções em instituições e comunidades" (ANDERSON; HERR, 2016, p.5).

Deste modo, o envolvimento das participantes no processo de investigação-ação se deu não apenas em uma relação verticalizada de pesquisador com as participantes, mas as próprias docentes pesquisadas transformaram-se, em certo momento, também em pesquisadoras de sua atuação, encontrando caminhos e construindo estratégias para melhorar seu trabalho e resolver demandas de sua prática.

Existem, pois, diferentes modelos de Investigação-ação (CAMPOS, 2012), porém, neste estudo, o modelo de Kemmis foi tomado como referência para o caminho metodológico proposto. Campos (2012), afirma que o modelo de Investigação-ação de 
Kemmis integra quatro momentos em espiral: planificar, agir, observar e refletir e, segundo Kemmis e McTaggart (1982 apud CAMPOS, 2012, p. 86), "estes momentos implicam reflexão sobre cada um dos ciclos de Investigação-ação, de forma a ir gerando, um conhecimento que apoie a preparação da ação do ciclo seguinte".

O curso, no qual se baseou este estudo, buscou seguir esta espiral iniciando-se a partir do "planejamento" da formação, considerando para isso, a base teórica que amparou esta pesquisa, o que resultou na criação do ambiente formativo em plataforma Moodle com propostas de atividades cujo intuito foi levar os participantes à reflexão sobre sua ação docente, na busca de soluções para suas demandas. A "ação", segundo estágio da espiral, realizou-se a partir da própria execução do curso, o qual contou com a participação ativa das professoras, produzindo conhecimentos, planejando suas estratégias e interagindo no ambiente, e com as intervenções da tutora durante a realização das atividades e nas reuniões online de orientação. A partir da realização do curso, deuse a "observação" das ações das participantes, terceiro estágio da espiral, que se orientou a partir da consulta aos registros nos fóruns de interação, aos planos de aprendizagem produzidos pelas docentes participantes e materiais didáticos criados na ferramenta de autoria. Após a observação, consolidou-se, a "reflexão", que materializou os resultados apresentados da pesquisa a partir da análise e interpretação dos dados obtidos em todo o processo.

É necessário salientar que a formação docente norteadora desta pesquisa buscou apoiar-se na perspectiva da racionalidade prática, com foco em um ensino reflexivo, com a finalidade de promover uma parceria colaborativa entre os participantes, como forma de romper com a racionalidade técnica a qual tem o professor como executor instrumental do currículo. Nesse sentido, Rosa e Schnetzler (2003) afirmam que, "Na parceria colaborativa, a reflexão e a intervenção na realidade se viabilizam a partir da interação entre pares que assumem papéis específicos no processo" (ROSA; SCHNETZLER, 2003, p. 28), o que, na formação proposta, foi promovido a partir das atividades de interação e troca de experiências nos fóruns.

No que se refere à ferramenta tecnológica de autoria utilizada pelas participantes para hospedar os materiais de apoio produzidos, dentre diversas ferramentas pesquisadas no planejamento do curso, a escolha foi pelo 'Publicador', ferramenta de autoria online desenvolvida pelo NEAD da Universidade Estadual Paulista (UNESP), que mostrou-se como melhor opção por: ser gratuita, funcionar em ambiente totalmente online sem necessidade de instalação, mostrar-se intuitiva e de fácil manuseio e por apresentar 
recursos básicos de acessibilidade, características estas, que não foram encontradas somadas nas demais ferramentas de autoria conhecidas. O 'Publicador' permite o compartilhamento público de materiais didáticos para estudo e possibilita a inserção de imagens, textos, vídeos, arquivos e links externos, dando flexibilidade e liberdade ao professor para construir seu material de acordo com as demandas e com participação de seus estudantes, permitindo que os materiais criados possam ser reutilizados por outros professores favorecendo uma rede colaborativa de saber em prol da educação.

$\mathrm{Na}$ análise dos dados da pesquisa, foram consideradas quatro fontes de evidências: as respostas das participantes nos fóruns de interação, os textos de planejamento das propostas de aprendizagem produzidas pelas professoras, os materiais didáticos construídos na ferramenta de autoria 'Publicador' e o questionário aberto de autoavaliação final do curso. Após a coleta dessas informações, elas foram importadas e organizadas no software de análise de dados MAXQDA, versão Standard 2018, identificando cada professora participante por uma letra do alfabeto, iniciando de A até I, de modo a garantir o anonimato na pesquisa. E uma vez organizados os dados e gerado o corpus da pesquisa, o material foi explorado a partir de uma leitura flutuante, em um momento de pré-análise que buscou obter uma visão geral da amostra e levantar as primeiras hipóteses referentes aos dados coletados. E após a leitura inicial das informações coletadas, foram criados dois códigos referentes aos temas de discussão principal nas análises, que foram denominados: alinhamento com a abordagem CCS e articulação com a base de conhecimentos do modelo TPACK.

Posteriormente, foram criados outros subcódigos para identificar a presença de elementos referentes aos assuntos abordados nos dois códigos principais de modo a facilitar o reconhecimento deles nos trechos da amostra. Os subcódigos que indicam alinhamento com a abordagem CCS foram: valoriza os conhecimentos prévios do estudante; busca promover transformações à realidade do aprendiz; tem significado ao aprendiz; contextualiza-se com a realidade do aprendiz; propõe a participação ativa do aprendiz; propõe a resolução de problemas relacionados à vivência; trabalha conceitos a partir dos interesses do estudante; propõe a criação de um produto final com uso da tecnologia; estimula a exploração, pesquisa e reflexão. Já os subcódigos referentes à articulação com a base de conhecimentos do TPACK são: demonstrou Conhecimento de Conteúdo $(C K)$; demonstrou Conhecimento Pedagógico $(P K)$; demonstrou Conhecimento Tecnológico (TK); articulou de forma integrada os três conhecimentos da base TPACK. 
A partir da criação desses códigos e subcódigos, os dados foram explorados mais profundamente com novas leituras e destaque de informações relevantes que faziam referência aos objetivos específicos do estudo relacionando trechos importantes com cada código e seus subcódigos. A interpretação de cada publicação construída no 'Publicador' foi correlacionada com seu plano de aprendizagem, as respostas nos fóruns e com a autoavaliação final, buscando-se identificar a forma pela qual a proposta criada por cada uma das participantes e o material produzido aproximavam-se do que versa a abordagem CCS e como se apresentavam considerando as características do modelo TPACK.

Finalmente, após realizar a exploração do material, analisar codificações geradas, após a triangulação dos dados e com base nas interpretações da pesquisadora considerando o referencial teórico estudado, foram levantados os resultados da pesquisa buscando elucidar os objetivos propostos.

\section{Alguns dados da pesquisa}

Visando nortear o leitor sobre os resultados que serão apresentados adiante, esta seção traz alguns dos dados relevantes obtidos com o estudo que irão contextualizar a pesquisa e ilustrar seu aproveitamente ante os objetivos amejados. Assim, cabe aqui apresentar as expectativas iniciais e como as nove participantes encerraram a etapa de formação avaliando seu percurso, como demonstra o Quadro 1 a seguir.

Quadro 1: Expectativas iniciais em relação ao curso x resultados alcançados

\begin{tabular}{|c|c|c|}
\hline Participante & Expectativas iniciais & Questionário de autovaliação final \\
\hline Prof.C & $\begin{array}{l}\text { [...] preciso adquirir } \\
\text { ferramentas nessa área, para } \\
\text { enriquecer minha prática } \\
\text { pedagógica. Espero contribuir, } \\
\text { de alguma forma, com todos } \\
\text { que participam do curso. }\end{array}$ & $\begin{array}{l}\text { A partir dessa abordagem, passei a enxergar melhor meu aluno como } \\
\text { sujeito do saber, de sua própria aprendizagem, que precisa estar } \\
\text { ligada a seu contexto de vivência, seu cotidiano, ao que faz parte } \\
\text { desse aluno. [...] Entendo que a ferramenta Publicador pode } \\
\text { enriquecer em muito minha prática pedagógica, pois proporciona } \\
\text { diversas formas de preparar atividades interessantes e significativas. }\end{array}$ \\
\hline
\end{tabular}




\begin{tabular}{|c|c|c|}
\hline & & $\begin{array}{l}\text { Achei o curso enriquecedor, motivador e inovador. Sugiro que haja } \\
\text { uma Pós com o mesmo tema. }\end{array}$ \\
\hline Prof. D & $\begin{array}{l}\text { [...] espero aprender muito } \\
\text { para colocar em prática os } \\
\text { ensinamentos } \\
\text { compartilhados. }\end{array}$ & $\begin{array}{l}\text { O curso serviu para ampliar os horizontes da minha prática } \\
\text { pedagógica. Através do compartilhamento dos materiais no } \\
\text { publicador e da troca das experiências podemos criar aulas mais } \\
\text { interessantes. [...] O curso me fez realmente repensar o que a minha } \\
\text { prática pedagógica está acrescentando para o aprendizado deles, } \\
\text { pois vi que tudo tem de ser contextualizado e com significado } \\
\text { relevante para o desenvolvimento da aprendizagem dos alunos. }\end{array}$ \\
\hline Prof. E & $\begin{array}{l}\text { Minha expectativa com o curso } \\
\text { é aprender mais e poder passar } \\
\text { para os alunos o que eu colher } \\
\text { de melhor. }\end{array}$ & $\begin{array}{l}\text { Hoje percebo como é importante saber o que os alunos pensam a } \\
\text { respeito do que está sendo trabalhado. Mesmo sendo tão pequenos, } \\
\text { vi como ficaram empolgados em dar sua opinião e poder se } \\
\text { expressar. [...] Vi como é importante a participação do aluno e como } \\
\text { tenho que mudar minha percepção de aprendizagem. Temos que } \\
\text { sempre trabalhar junto com os alunos e com sua vivencia pois eles já } \\
\text { vem de casa com uma bagagem, isso é muito importante para uma } \\
\text { aprendizagem significativa. }\end{array}$ \\
\hline Prof. F & $\begin{array}{l}\text { O curso é uma chance de estar } \\
\text { tecnologicamente mais } \\
\text { atualizada. E é isto que } \\
\text { pretendo levar a meus alunos o } \\
\text { uso inteligente e consciente da } \\
\text { tecnologia atual em nossa vida } \\
\text { com o que sei e com o que irei } \\
\text { aprender neste curso. }\end{array}$ & $\begin{array}{l}\text { O publicador e o curso me mostrou uma maneira mais prática e fácil } \\
\text { de montar uma aula e expor aos alunos. [...] tratar do assunto } \\
\text { escolhido com ajuda de ferramentas como a tecnologia tornou a } \\
\text { proposta de ensino que criei mais atrativa e interessante aos olhos } \\
\text { dos alunos. [...] Foi uma experiência de muito aproveito que será } \\
\text { levada para a prática sempre. }\end{array}$ \\
\hline Prof. G & $\begin{array}{l}\text { Espero que este curso } \\
\text { contribua para que eu conheça } \\
\text { novasferramentas tecnológicas } \\
\text { para integrar ao meu trabalho, } \\
\text { além disso, espero que seja } \\
\text { uma oportunidade para } \\
\text { trocarmos experiências, pois } \\
\text { acredito que nosso trabalho em } \\
\text { sala de aula é parte da nossa } \\
\text { formação inicial e contínua, } \\
\text { assim como também é fruto } \\
\text { dessas trocas de experiências. }\end{array}$ & $\begin{array}{l}\text { [..] essa proposta de curso me levou a ficar ainda mais atenta a } \\
\text { importância da participação dos alunos em todo o processo de } \\
\text { aprendizagem. [...] A abordagem CCS contribuiu para que eu } \\
\text { buscasse atividades de interesse dos alunos, inclusive na escolha do } \\
\text { tema, e que ao mesmo tempo fossem significativas, pois havia sempre } \\
\text { a preocupação de que fossem atividades interativas, que os } \\
\text { ajudassem a compreender os conceitos envolvidos no tema e ainda } \\
\text { usando recursos e ferramentas que facilitavam a eles a autonomia e } \\
\text { a construção do próprio conhecimento.[...] O uso da ferramenta } \\
\text { Publicador foi muito importante para organizar todos os recursos } \\
\text { usados nas aulas, facilitando o acesso a outras ferramentas e } \\
\text { participação dos alunos. }\end{array}$ \\
\hline Prof. H & $\begin{array}{l}\text { [...] aprender muito mais sobre } \\
\text { a tecnologia na educação, pois } \\
\text { eu como sendo professora de } \\
\text { informática, não vejo cursos na } \\
\text { área, já procurei em vários } \\
\text { lugares e não achei. }\end{array}$ & $\begin{array}{l}\text { Percebi com o curso que quando o alunos participam da construção } \\
\text { do projeto, há mais interação e a aprendizagem fica mais } \\
\text { significativa, e o ccs me fez relembrar o quanto é importante essa } \\
\text { prática em sala de aula. [...] conheci ferramentas novas que passam } \\
\text { despercebidas no dia a dia e o uso do Publicador fez com que os } \\
\text { alunos se sentissem autores da sua própria aprendizagem. }\end{array}$ \\
\hline Prof. I & Buscar novos conhecimentos. & $\begin{array}{l}\text { O curso me deu várias ideias, contribuiu para reforçar minha prática } \\
\text { em sala de aula, considerando sempre o aluno como autor. O } \\
\text { Publicador é uma ferramenta muito fácil de utilizar e complementa } \\
\text { de forma significativa o trabalho em sala de aula que considera o } \\
\text { aluno como autor de sua aprendizagem. }\end{array}$ \\
\hline
\end{tabular}

Fonte: Elaborado pela autora com dados extraídos do Fórum 1 e da Autoavaliação final

\section{O curso de formação realizado dentro da pesquisa pelas participantes se organizou}

em cinco momentos conforme apresentado a seguir: Tópico 1 - Introdução à formação: contextualizando e pensando as expectativas; Tópico 2 - Investigando recursos que favoreçam a aprendizagem com uso das tecnologias; Tópico 3 - Conhecendo a ferramenta Publicador; Tópico 4 - Construindo uma proposta de aprendizagem com uso do Publicador; e Tópico 5 - Aplicação da proposta inovadora e compartilhamento dos resultados. Tais tópicos buscaram partilhar um pouco do que as participantes já conheciam e utilizavam sobre tecnologias em suas práticas e revelar os conhecimentos 
que iam adquirindo ao longo do curso com relatos em fóruns e tarefas de planejamento e criação de materiais didáticos, alinhados a um projeto criado por elas para assuntos a serem trabalhados com seus aprendizes demonstrando que o curso desenvolveu-se de forma colaborativa, interativa, contextualizada e significativa como propõe a abordagem CCS.

O conjunto das atividades do curso resultou nos arquivos dos planos de aprendizagem dentro de um projeto temático que seria trabalhado com os estudantes, e estes planos serviram de base para que as professoras construissem seus materiais didáticos na ferramenta de autoria 'Publicador' que seria acessada pelos alunos. Dentre os dados que emergiram nesse processo algumas postagens mostraram-se relevantes, revelando competências das docentes como mostram os exertos que seguem referindo-se a capacidade de ser autodidata, de desenvolver curiosidade e buscar a própria formação:

\begin{abstract}
Em experiências anteriores utilizei sempre esse espaço do laboratório de informática para pesquisas. [...] estamos (a Professora B e outros docentes do seu grupo de trabalho) realizando estudos e discussões para compreender melhor o assunto e poder realizar as intervenções [...] Estamos aos poucos lendo artigos, fazendo pesquisas, discussões. (Professora B - Fórum 2)

Planejo as minhas aulas semanalmente e utilizo muito a internet como ferramenta de busca e complementação de conteúdos. De acordo com a matéria, o assunto, realizo pesquisas para aprender mais e ampliar o conhecimento [...] Realizo pesquisas e planejo as aulas conforme os conteúdos do bimestre e as necessidades dos alunos (Professora D - Fórum 2)
\end{abstract}

Já na ilustração a seguir, Figura 2, postada pela Professora C como atividade inicial de sua proposta de projeto, é possível visualizar como ela, a partir de uma intervenção pedagógica criativa utiliza com proficiência os recursos da ferramenta 'Publicador' para levar seus alunos à reflexão, levantar os conhecimentos prévios dos aprendizes, construir o saber de forma coletiva, ou seja, compartilhando com os colegas, e relacionando aprendizagens com vivências de modo a promover mudanças na forma de agir diante de sua realidade, pressuposto da abordagem CCS, e demonstrando também assim a junção de conhecimentos pedagógicos, tecnológicos e de conteúdo de forma integrada, como exige o modelo TPACK. 
Figura 2: Exemplo de postagem criativa da Professora C no Publicador para introduzir discussão sobre o tema Preconceito e Diversidade

\begin{tabular}{|l|l|}
\hline Acervo do Saber \\
Oespaço onde o conhecimento è compartihado
\end{tabular}
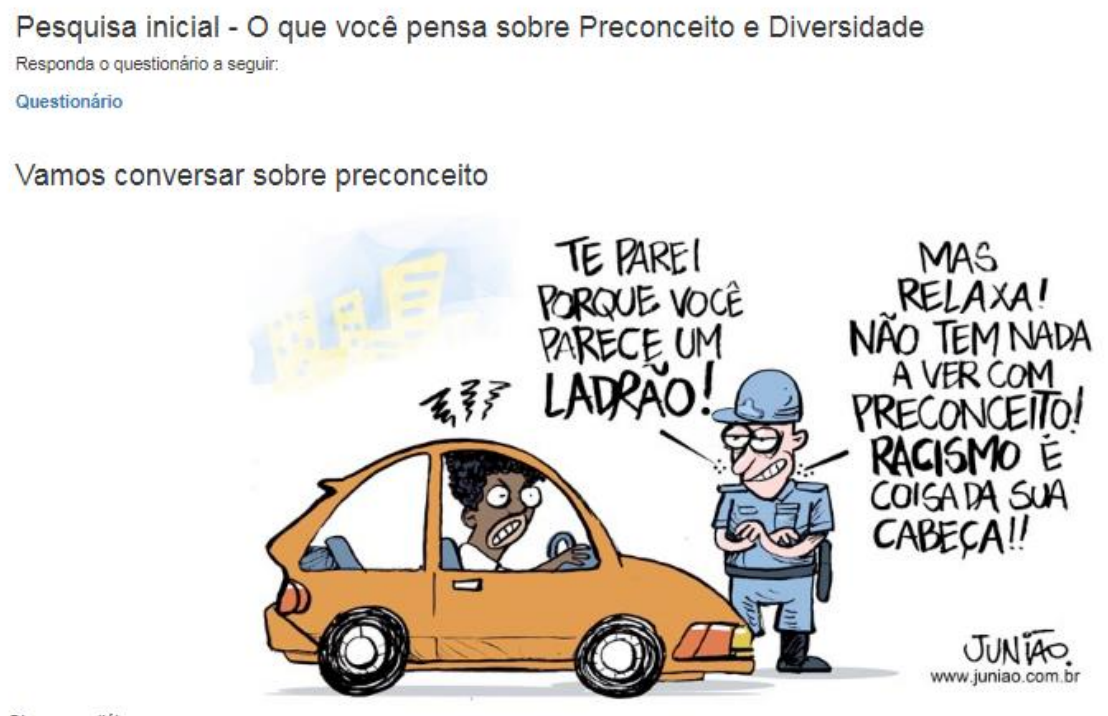

Fonte: Imagem capturada da ferramenta Publicador

Diversas outras passagens coletadas evidenciam os resultados que serão apresentados a seguir, porém para não extrapolar na extensão deste artigo esses dados detalhados não serão aqui exibidos. Sendo assim, a seção seguinte traz os resultados do estudo.

\section{Resultados}

Os resultados encontrados apontaram que é possível desenvolver ações formativas para uso da ferramenta autoral que preparem o professor para uma atuação mais autônoma, capaz de levar os alunos a construírem o conhecimento de forma significativa e não apenas se apropriarem de informações que a eles são transmitidas, como mostra um dos exertos extraídos da autoavaliação final do curso:

Gostei muito de conhecer as possibilidades que a ferramenta Publicador oferece, bem como as outras ferramentas que conheci, como Autodraw, Padlet e Canva.[...] A construção da proposta mudou minha visão e reforçou $o$ quanto os alunos precisam interagir com o objeto de conhecimento para apropriar-se dele e dar significado ao saber elaborado. [...] a ferramenta Publicador é aberta e por isso permite que o professor desenvolva seu trabalho de acordo com a abordagem CCS, permitindo uma mediação que 
trate o aluno como autor. [...] conhecer as estratégias das outras professoras sempre enriquece ou provoca reflexões sobre o nosso trabalho. (Professora B - Autoavaliação do curso)

Em relação à proficiência das participantes na criação de materiais na ferramenta de autoria 'Publicador', houve uma apropriação satisfatória de 8 das 9 participantes, que demonstraram uma séria de competências docentes que merecem destaque quando se pensa na formação docente e no que pode ser estimulado neste processo.

Segundo Roldão (2003, apud DIAS, 2010, p.75), a competência surge quando, "perante uma situação, o sujeito é capaz de mobilizar adequadamente diversos conhecimentos prévios, selecioná-los e integrá-los de forma ajustada à situação em questão", trata-se "[...] de uma combinação de conhecimentos, motivações, valores e ética, atitudes, emoções, bem como outros componentes de carácter social e comportamental que, em conjunto, podem ser mobilizados para gerar uma ação eficaz num determinado contexto" (DIAS, 2010, p. 75).

Nesse sentido, desenvolver a competência "exige apropriação sólida e ampla de saberes e [...] recorre, desta forma, a noções, conhecimentos, informações, procedimentos, métodos e técnicas" (DIAS, 2010, p. 74).

No contexto da formação continuada realizada para esta pesquisa, foi possível elencar algumas competências necessárias ao professor na atuação como autor de seus materiais didáticos personalizados, considerando para isso os conhecimentos do modelo TPACK.

As competências relacionadas ao conhecimento de conteúdo, dizem respeito aos saberes do professor em relação aos conceitos e conteúdos abordados no processo de ensino que ele pretende que seus estudantes aprendam, por isso precisa ter profundo domínio. Em relação a esse tipo de conhecimento, foi possível identificar que o professor, precisa desenvolver as seguintes competências: 'ser autodidata', o que inclui também fomentar em si a vontade de querer aprender sempre mais, pesquisar e aprofundar-se nos temas já conhecidos, afinal, como afirmou Bispo (2015) e Libâneo (2010), os professores precisam ter sólida cultura geral, precisam tornar-se pesquisadores para assim atuarem como autores, saber aprender a aprender; 'ser prudente', competência esta que refere-se a ação do docente de ser reflexivo em relação às informações a que tem acesso, buscando confiabilidade das fontes consultadas, filtrando os conteúdos selecionados de modo a conferir segurança aos conceitos que ensina e, além disso, analisar os dados e fontes de conhecimentos levantados pelos estudantes, procurando sempre o caminho ético da 
verdade, citando a origem das informações apresentadas, fazendo uma curadoria dos conteúdos educacionais que seja "capaz de superar as pressões e apelos de consumo e mercantilização do conhecimento" (LOPES; SOMMER; SCHMIDT, 2014, p. 70).

As competências relacionadas ao conhecimento pedagógico dizem respeito a como o professor se articula e cria suas estratégias para fazer seu estudante aprender, são saberes construídos com estudos e experiências vivenciadas, erros e acertos que levam à evolução do saber docente, uma vez que segundo Tardif (2002), são os professores os principais atores e mediadores culturais dos saberes escolares. Assim, para a construção de materiais didáticos personalizados a partir da ferramenta de autoria 'Publicador', observou-se que é preciso que os docentes mobilizem as seguintes competências relacionadas ao conhecimento pedagógico: 'Ser motivado e reconhecer a motivação no outro', motivar-se e motivar o estudante, envolvendo-o com suas próprias aprendizagens, já que a motivação é resultado de uma série de fatores que envolvem interesse, persistência, determinação, aspiração e realização pessoal (BERALDO; MACIEL, 2016). Nesse sentido, considerar os anseios e conhecimentos prévios do aprendiz, tornar a aprendizagem significativa é fundamental, como aponta a abordagem CCS (SCHLÜNZEN, 2000, 2015); Saber trabalhar em equipe, é outra competência pedagógica identificada no estudo, que diz respeito à capacidade dos docentes em colaborar com seus pares, assim como buscar apoio quando precisam e a esse respeito, Imbernón (2010) afirma que, a formação continuada deve promover mais do que atualização, deve ser capaz de criar espaços de formação, favorecendo o desenvolvimento docente de forma individual e coletiva e estabelecendo redes de troca entre os professores; Ser responsável por sua própria formação, outra competência que diz respeito à autonomia do professor, ou seja, ele por si próprio deve buscar meios para melhorar sua prática. Embora o curso tenha se configurado como uma formação continuada, ficou evidente que as professoras buscaram caminhos e novas aprendizagens baseadas em questões reais com as quais se deparavam no trabalho que propuseram, não esperando apenas que os elementos do curso suprissem todas as demandas surgidas, e neste contexto, Libâneo (2010) pontua que o professor precisa investir em sua atualização científica, técnica e cultural no processo de formação continuada, buscando atualizar-se frente às mudanças.

Imbernón (2010) acrescenta que, a formação continuada requer dar palavra aos professores e responsabilizá-los também por seu próprio desenvolvimento, permitindo que exerçam um papel construtivo e criativo no processo de planejamento e não um papel somente técnico em subordinação a um conhecimento que já recebe pronto; Compreender 
como seus estudantes aprendem e ensiná-los a aprender a aprender; essa talvez seja a competência mais importante do Saber Pedagógico para a produção de conteúdos personalizados, uma vez que o professor só conseguirá levar seu estudante à aprendizagem a partir do momento em que compreender suas formas de interpretar, de compreender e lidar com as informações e sobretudo se reconhecer os canais e recursos que poderá utilizar para favorecer o contato do estudante com o objeto do conhecimento e levá-lo a compreender as exigências de uma atividade para responder adequadamente a elas, como aponta Libâneo (2010). Ainda a respeito dessa competência elencada, o papel do professor vai além de um propositor de tarefas com uso da tecnologia. Seu papel "é central para gerar um ambiente de ensino capaz de suscitar situações de aprendizagem envolventes e significativas" (SOUSA; SCHLÜNZEN JUNIOR, 2018, p. 110).

Quanto às competências relacionadas ao conhecimento tecnológico, os saberes relacionados ao uso eficiente e proficiente dos recursos tecnológicos no processo de ensino e aprendizagem, foram identificadas as seguintes competências necessárias: Ser curioso - Para produzir materiais didáticos usando a tecnologia, o professor precisa ser alfabetizado digitalmente, porém, segundo Tarouco (2019), é preciso que os professores desenvolvam mais do que sua alfabetização digital, os docentes precisam de fluência digital, a qual diz respeito à capacidade de reformular conhecimentos, expressar-se de modo criativo e apropriado no contexto, bem como produzir e gerar nova informação e não apenas compreendê-la. Por isso, ter curiosidade e buscar sempre aprender e conhecer novos recursos tecnológicos é pressuposto para que o professor crie e use a tecnologia no ensino; 'Ser proficiente', que diz respeito a saber utilizar a tecnologia, conhecer seus recursos, suas possibilidades e limites envolvidos no processo de ensino e aprendizagem proposto. Segundo Libâneo (2010), o docente precisa reconhecer o impacto das TDIC na sala de aula e considerá-las como ferramentas para o processo educativo, porém não meramente como recursos didáticos, mas servindo para orientar discussões e preencher lacunas do que não tenha sido aprendido, e para que isso ocorra, ser proficiente no uso das ferramentas é fundamental; 'Ser criativo', que trata-se de um saber que implica em dar novas funções a mesmos recursos tecnológicos em contextos diferentes de acordo com as demandas. Na própria criação e seleção de recursos para compor seus materiais, o professor precisa lançar mão da criatividade de modo a tornar o contato com os materiais prazeroso e significativo ao estudante. Nesse sentido, o uso de uma ferramenta de autoria abre novas possibilidades para desenvolver a criatividade do professor numa atuação autoral, que "remete a ações que agregam copiar, colar, remixar, distribuir, fazer 
circular ideias e conceitos" (LOPES; SOMMER; SCHMIDT, 2014, p.67). Assim, ser criativo requer dar vida às ideias, pensar sobre os objetivos educacionais com uma mente aberta às diversas possibilidades que uma ferramenta de autoria oferece.

Por fim, esta seção se encerra concordando com o que aponta Dias (2010), quando afirma que "uma abordagem por competências defende que o sujeito constrói os seus próprios saberes, numa interação que possibilita o aprender a aprender" (DIAS, 2010, p. 77). Assim, foi possível constatar que as competências necessárias para construção de materiais didáticos a partir da ferramenta de autoria Publicador são desenvolvidas a partir da prática, das necessidades e demandas surgidas no processo de planejamento de ensino, em uma autoformação das próprias docentes que evoluem a cada nova conquista.

Quanto à proposta de formação, foi possível observar que o modelo semipresencial com tutoria e oportunidade de vivência das participantes num curso organizado de acordo com a abordagem CCS, colaborou para a compreensão da abordagem por parte das participantes, o que se refletiu na construção de seus planos de aprendizagem e materiais didáticos, que demonstraram diversos elementos alinhados a abordagem CCS, representando avanços nas práticas docentes voltadas a um ensino com participação ativa dos estudantes e uma aprendizagem contextualizada e significativa. $O$ Quadro 2 a seguir, mostra que todas as propostas criadas apresentaram em seus planejamentos ações que remetem aos pressupostos da abordagem CCS, sendo seis delas mais representativas por apresentarem mais características da abordagem alcançadas.

Quadro 2: Elementos de alinhamento à abordagem CCS nos planos de aprendizagem

\begin{tabular}{|c|c|c|c|c|c|c|c|c|c|}
\hline Temas & 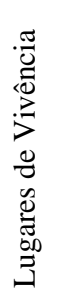 & 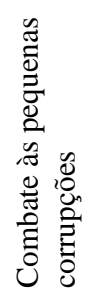 & 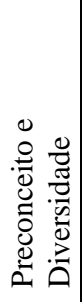 & 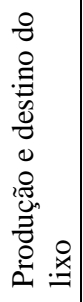 & 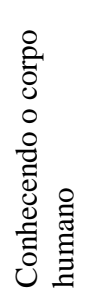 & 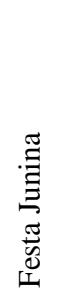 & 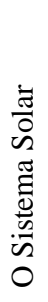 & 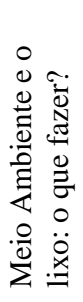 & 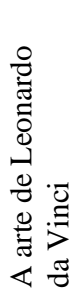 \\
\hline $\begin{array}{l}\text { Valoriza os conhecimentos } \\
\text { prévios do estudante }\end{array}$ & & $\mathrm{X}$ & $\mathrm{X}$ & $\mathrm{X}$ & $\mathrm{X}$ & $\mathrm{x}$ & $\mathrm{x}$ & $\mathrm{x}$ & $\mathrm{X}$ \\
\hline $\begin{array}{l}\text { Busca promover transformações } \\
\text { à realidade do aprendiz }\end{array}$ & & $\mathrm{x}$ & $\mathrm{x}$ & $\mathrm{x}$ & $\mathrm{x}$ & & $\mathrm{x}$ & $\mathrm{x}$ & \\
\hline Tem significado ao aprendiz & $\mathrm{x}$ & $\mathrm{x}$ & $\mathrm{x}$ & $\mathrm{x}$ & $\mathrm{x}$ & & $\mathrm{x}$ & $\mathrm{x}$ & $\mathrm{x}$ \\
\hline $\begin{array}{l}\text { Contextualiza-se com a realidade } \\
\text { do aprendiz; }\end{array}$ & $\mathrm{X}$ & $\mathrm{X}$ & $\mathrm{X}$ & $\mathrm{X}$ & $\mathrm{X}$ & $\mathrm{X}$ & $\mathrm{x}$ & $\mathrm{x}$ & \\
\hline $\begin{array}{l}\text { Propõe a participação ativa do } \\
\text { aprendiz }\end{array}$ & $\mathrm{x}$ & $\mathrm{x}$ & $\mathrm{x}$ & $\mathrm{x}$ & $\mathrm{x}$ & $\mathrm{x}$ & $\mathrm{x}$ & $\mathrm{x}$ & $\mathrm{x}$ \\
\hline $\begin{array}{l}\text { Propõe a resolução de problemas } \\
\text { relacionados à vivência }\end{array}$ & & & $\mathrm{x}$ & $\mathrm{x}$ & & & & $\mathrm{x}$ & \\
\hline
\end{tabular}




\begin{tabular}{|l|c|c|c|c|c|c|c|c|c|}
\hline $\begin{array}{l}\text { Trabalha conceitos a partir dos } \\
\text { interesses do estudante }\end{array}$ & $\mathrm{x}$ & $\mathrm{x}$ & & & $\mathrm{x}$ & & $\mathrm{x}$ & $\mathrm{x}$ & \\
\hline $\begin{array}{l}\text { Propõe a criação de um produto } \\
\text { final com uso da tecnologia }\end{array}$ & $\mathrm{x}$ & $\mathrm{x}$ & $\mathrm{x}$ & $\mathrm{x}$ & $\mathrm{x}$ & $\mathrm{x}$ & $\mathrm{x}$ & $\mathrm{x}$ & $\mathrm{x}$ \\
\hline $\begin{array}{l}\text { Estimula a exploração, pesquisa e } \\
\text { reflexão }\end{array}$ & $\mathrm{x}$ & $\mathrm{x}$ & $\mathrm{x}$ & $\mathrm{x}$ & & & $\mathrm{x}$ & $\mathrm{x}$ & $\mathrm{x}$ \\
\hline
\end{tabular}

Fonte: Elaboração própria

Já o Quadro 3, a seguir, refere-se à presença de elementos da abordagem CCS nos materiais didáticos produzidos no 'Publicador', buscando, após sua observação, comparar a presença dos elementos da abordagem CCS nos planos com sua presença também nos materiais didáticos criados.

Quadro 3: Elementos de alinhamento à abordagem CCS nos materiais criados no Publicador

\begin{tabular}{|c|c|c|c|c|c|c|c|c|c|}
\hline Temas & 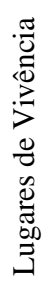 & 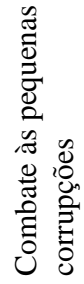 & 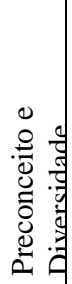 & 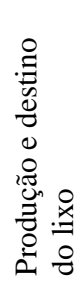 & 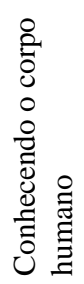 & 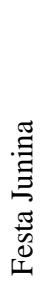 & 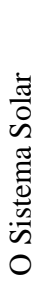 & 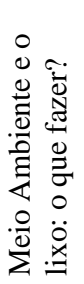 & 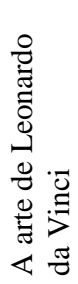 \\
\hline $\begin{array}{l}\text { Valoriza os conhecimentos } \\
\text { prévios do estudante }\end{array}$ & $\mathrm{X}$ & $\mathrm{x}$ & $\mathrm{X}$ & $\mathrm{X}$ & & & $\mathrm{x}$ & $\mathrm{X}$ & \\
\hline $\begin{array}{l}\text { Busca promover transformações } \\
\text { à realidade do aprendiz }\end{array}$ & & $\mathrm{X}$ & $\mathrm{X}$ & $\mathrm{X}$ & & & & $\mathrm{x}$ & \\
\hline Tem significado ao aprendiz & $\mathrm{X}$ & $\mathrm{X}$ & $X$ & X & $\mathrm{x}$ & & $\mathrm{x}$ & $\mathrm{x}$ & \\
\hline $\begin{array}{l}\text { Contextualiza-se com a realidade } \\
\text { do aprendiz; }\end{array}$ & $\mathrm{X}$ & $\mathrm{x}$ & $\mathrm{X}$ & $\mathrm{X}$ & $\mathrm{x}$ & & $\mathrm{x}$ & $\mathrm{x}$ & \\
\hline $\begin{array}{l}\text { Propõe a participação ativa do } \\
\text { aprendiz }\end{array}$ & $\mathrm{x}$ & $\mathrm{x}$ & $\mathrm{X}$ & $\mathrm{X}$ & & $\mathrm{x}$ & $\mathrm{x}$ & $\mathrm{x}$ & \\
\hline $\begin{array}{l}\text { Propõe a resolução de problemas } \\
\text { relacionados à vivência }\end{array}$ & & & $\mathrm{X}$ & $\mathrm{X}$ & & & & $\mathrm{x}$ & \\
\hline $\begin{array}{l}\text { Trabalha conceitos a partir dos } \\
\text { interesses do estudante }\end{array}$ & $\mathrm{x}$ & $\mathrm{X}$ & & & $\mathrm{x}$ & & $\mathrm{x}$ & $\mathrm{x}$ & \\
\hline $\begin{array}{l}\text { Propõe a criação de um produto } \\
\text { final com uso da tecnologia }\end{array}$ & & $\mathrm{x}$ & $\mathrm{X}$ & $\mathrm{X}$ & $\mathrm{X}$ & $\mathrm{x}$ & $\mathrm{x}$ & $\mathrm{x}$ & \\
\hline $\begin{array}{l}\text { Estimula a exploração, pesquisa } \\
\text { e reflexão }\end{array}$ & $\mathrm{X}$ & $\mathrm{x}$ & $\mathrm{X}$ & $\mathrm{x}$ & & $\mathrm{x}$ & $\mathrm{x}$ & $\mathrm{x}$ & \\
\hline
\end{tabular}

Fonte: Elaboração própria

Como observado no Quadro 3, seis dos nove planos, que tiveram ao menos seis características da abordagem CCS no conjunto dos seus planos confrontados com os materiais didáticos criados, representaram avanços na forma das docentes incluírem em sua prática a abordagem CCS.

Quanto à proficiência e ao letramento digital das professoras participantes na ferramenta de autoria 'Publicador', foi possível observar que quase todas as participantes 
compreenderam o manuseio técnico da ferramenta, uma vez que fizeram uso dos diferentes recursos conforme apontado no Quadro 4, sendo que apenas uma delas apresentou desempenho inferior por não usar recursos importantes disponíveis.

Quadro 4: Ocorrência dos temas levantados referentes à proficiência na ferramenta de autoria

\begin{tabular}{|c|c|c|c|c|c|c|c|c|c|}
\hline Temas & 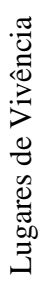 & 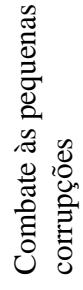 & 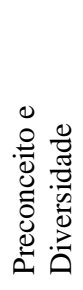 & 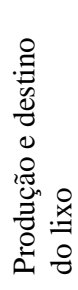 & 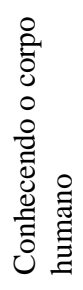 & 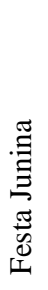 & 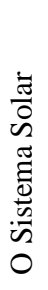 & 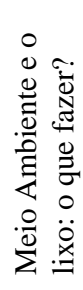 & 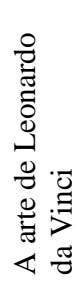 \\
\hline $\begin{array}{l}\text { Conteúdo que solicita } \\
\text { interação/participação }\end{array}$ & $\mathrm{x}$ & $\mathrm{X}$ & $\mathrm{X}$ & $\mathrm{x}$ & $\mathrm{x}$ & $\mathrm{x}$ & $\mathrm{x}$ & $\mathrm{X}$ & \\
\hline $\begin{array}{l}\text { Imagens para reflexão/ apoio às } \\
\text { atividades }\end{array}$ & $\mathrm{x}$ & $\mathrm{x}$ & $\mathrm{x}$ & $\mathrm{x}$ & $\mathrm{x}$ & & & $\mathrm{x}$ & \\
\hline Texto informativo & $\mathrm{x}$ & $\mathrm{x}$ & $\mathrm{x}$ & $\mathrm{x}$ & $\mathrm{x}$ & $\mathrm{x}$ & $\mathrm{x}$ & $\mathrm{x}$ & $\mathrm{x}$ \\
\hline Vídeo ilustrativo & $\mathrm{x}$ & $\mathrm{x}$ & $\mathrm{x}$ & $\mathrm{x}$ & $\mathrm{x}$ & $\mathrm{x}$ & $\mathrm{x}$ & $\mathrm{x}$ & $\mathrm{x}$ \\
\hline Imagem ilustrativa & $\mathrm{x}$ & $\mathrm{x}$ & $\mathrm{x}$ & $\mathrm{x}$ & $\mathrm{x}$ & $\mathrm{x}$ & $\mathrm{x}$ & $\mathrm{x}$ & $\mathrm{x}$ \\
\hline Links para outros recursos na web & $\mathrm{x}$ & $\mathrm{X}$ & $\mathrm{x}$ & $\mathrm{x}$ & $\mathrm{x}$ & $\mathrm{x}$ & $\mathrm{x}$ & $\mathrm{x}$ & \\
\hline
\end{tabular}

Fonte: Elaboração própria

Porém, mesmo com resultados animadores, a articulação do material produzido observando-se a base de conhecimentos do modelo TPACK- mostrou que nas propostas 'Festa Junina' (Professora F) e 'Arte de Leonardo da Vinci' (Professora I), tal apropriação não se deu em sua plenitude quanto aos elementos voltados a ações didáticas de ensino que poderiam promover a aprendizagem dos estudantes, ou seja, há uma lacuna no que o TPACK chama de conhecimento pedagógico $(P K)$. Nas duas propostas citadas, poucos foram os elementos que buscaram promover a aprendizagem do estudanto levando-o à reflexão, pesquisa e construção do saber, uma vez que como afirma Moran (2004, p. 77), "o estudante precisa ultrapassar o papel de passivo, de escutar, ler, decorar [...] e tornarse criativo, crítico, pesquisador e atuante, para produzir conhecimento". Assim, considerando o que versa o modelo TPACK de Mishra e Koehler (2006), constatou-se que os materiais destas duas propostas não foram construídos alinhados à base de conhecimentos do modelo TPACK, já que não demonstraram conhecimentos pedagógicos $(P K)$ suficientes para promover a aprendizagem dos aprendizes, o que é demonstrado no Quadro 5, a seguir. 
Quadro 5: Alinhamento segundo o modelo TPACK relacionando as propostas de aprendizagem e os materiais produzidos na ferramenta de autoria

\begin{tabular}{|c|c|c|c|c|c|c|c|c|c|}
\hline Temas & 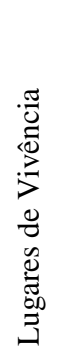 & 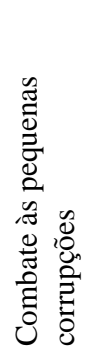 & 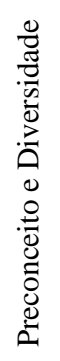 & 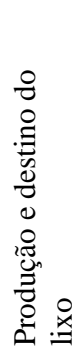 & 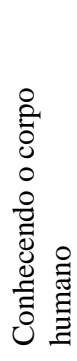 & 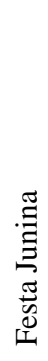 & 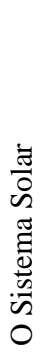 & 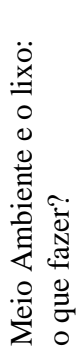 & 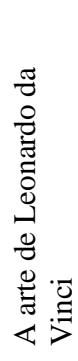 \\
\hline $\begin{array}{l}\text { Demonstrou Conhecimento de } \\
\text { Conteúdo }(\mathrm{CK})\end{array}$ & $\mathrm{X}$ & $\mathrm{X}$ & $\mathrm{X}$ & $\mathrm{X}$ & $\mathrm{X}$ & $\mathrm{X}$ & $\mathrm{X}$ & $\mathrm{X}$ & $\mathrm{X}$ \\
\hline $\begin{array}{l}\text { Demonstrou Conhecimento } \\
\text { Pedagógico (PK) }\end{array}$ & $\mathrm{X}$ & $\mathrm{X}$ & $x$ & $\mathrm{X}$ & $\mathrm{x}$ & & $\mathrm{X}$ & $\mathrm{x}$ & \\
\hline $\begin{array}{l}\text { Demonstrou Conhecimento } \\
\text { Tecnológico (TK) }\end{array}$ & $\mathrm{X}$ & $\mathrm{X}$ & $\mathrm{X}$ & $\mathrm{X}$ & $\mathrm{X}$ & $\mathrm{X}$ & $\mathrm{X}$ & $\mathrm{X}$ & $\mathrm{X}$ \\
\hline $\begin{array}{l}\text { Articulou os três conhecimentos da } \\
\text { base TPACK }\end{array}$ & $\mathrm{X}$ & $\mathrm{X}$ & $\mathrm{X}$ & $\mathrm{x}$ & X & & $\mathrm{X}$ & $\mathrm{X}$ & \\
\hline
\end{tabular}

Fonte: Elaboração própria.

Ambas as propostas, 'Festa Junina' (Professora F) e 'Arte de Leonardo da Vinci' (Professora I), não trouxeram questões para reflexão e aprendizagem, e nem atividades com as quais os estudantes pudesse aprender sobre os temas de forma satisfatória, apenas apresentaram textos com informações sobre os assuntos trabalhados, imagens ilustrativas dos temas como se fosse em um blog, demonstrando conhecimentos sobre os conteúdos propostos, sobre o uso da ferramenta tecnológica, porém sem nenhuma didática voltada ao ensino, apenas apresentando informações sem desenvolver a ação de ensino que pudesse levar os estudantes a refletir e aprender. A seguir é possível observar na Figura 3 uma imagem capturada no 'Publicador', o exemplo de como os materiais desses projetos eram organizados apenas com textos informativos e imagens ilustrativas. 
Figura 3: Exemplo de postagens da professora I na ferramenta 'Publicador' com imagem e texto

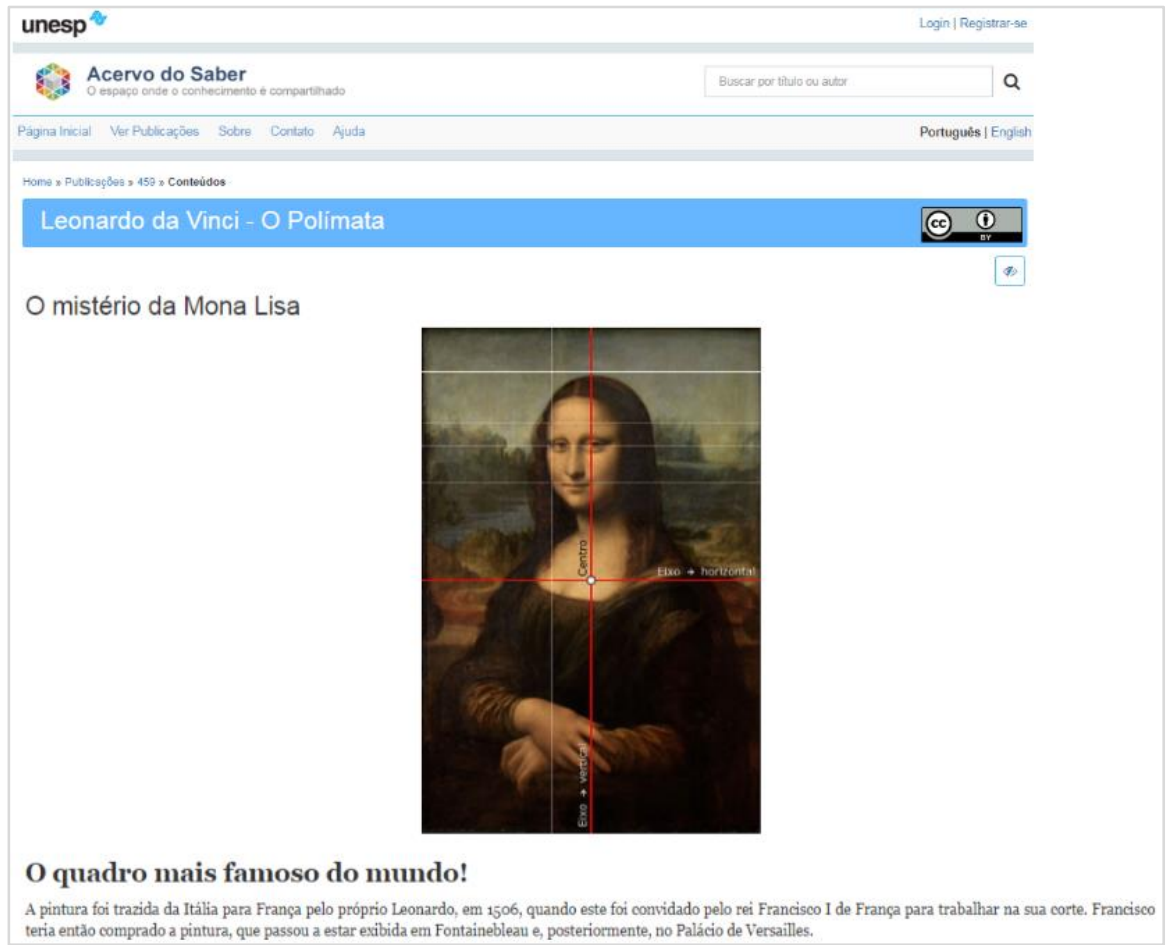

Fonte: Imagem capturada pela autora no ambiente Publicador utilizado para a pesquisa

Já as demais propostas apresentaram elementos que contemplaram os três conhecimentos que formam a base TPACK e demonstraram articulação conjunta desses conhecimentos nas ações propostas e materiais didáticos digitais criados de forma integrada, como versa a teoria de Mishra e Koehler (2006).

\section{Considerações finais}

Com base nos estudos e reflexões realizadas, foi possível concluir que, partindo do pressuposto de que o ciclo dos anos iniciais do Ensino Fundamental é uma etapa na qual o professor é generalista, sendo geralmente apenas ele quem trabalha os conteúdos escolares das diferentes áreas, essa fase apresenta um grande potencial para o desenvolvimento da aprendizagem segundo os princípios da abordagem CCS, uma vez que, o docente tem maior facilidade de trabalhar com projetos, integrando os conteúdos de diferentes campos do saber com a problematização a partir de temas geradores e propostas motivadoras, pensadas em parceria com os aprendizes e em consonância com suas vivências e anseios. Para fazer isso, no entanto, o estudo apontou a necessidade de formação continuada que leve o docente repensar sua ação, passando a assumir um papel de orientador e propositor de situações de aprendizagem, mediando o processo, motivando a curiosidade e a criticidade dos discentes, estimulando a pesquisa e o gosto 
pela descoberta em um aprender voltado a transformar a si próprio e a sua realidade, seu espaço de vivência.

Foi possível constatar, ainda, que, para a atuação com uso da ferramenta de autoria e recursos tecnológicos, o docente precisa ser letrado digitalmente, analisando as escolhas das tecnologias que utiliza com base nos objetivos pedagógicos, baseando-se nas distintas formas do aprendem de seus estudantes, de modo que em sua prática, eles aprofundem seu saber nos conteúdos desenvolvidos, para que dominem e apliquem, de forma integrada, a tríade conteúdo, métodos de ensino e proficiência das tecnologias envolvidas no processo de ensino, como versa o modelo TPACK.

O estudo mostrou que a formação semipresencial pode ser uma alternativa de qualificação dos professores para que desenvolvam uma prática pautada na abordagem CCS. No entanto, esse processo carece de acompanhamento constante por um tutor/formador que conheça a fundo a abordagem e tenha sensibilidade e respeito para intervir de modo eficiente para orientar o professor a uma reflexão rica sobre sua prática visando transformação e evolução.

A respeito das competências necessárias para a construção de materiais didáticos a partir de uma ferramenta de autoria online, foi observado que estas competências correspondem a uma combinação de saberes que se desenvolvem no sujeito perante um dado contexto que lhe exige mobilização dos conhecimentos prévios para agir. A partir do estudo, foi possível elencar algumas competências presentes nas docentes participantes que se mostraram importantes ao perfil de professor que se propõe a autor alinhando conhecimento de conteúdo, conhecimento pedagógico e tecnológico, são elas: ser autodidata; ser prudente; ser motivado e reconhecer a motivação no outro; saber trabalhar em equipe; ser responsável por sua própria formação contínua; compreender como os estudantes aprendem; ser curioso; ser proficiente nas tecnologias; ser criativo.

Em se tratando das limitações deste estudo, em relação à promoção da aprendizagem segundo o que versa a teoria de Mishra e Koehler (2006), emergiram duas questões pertinentes que suscitam novas reflexões, são elas: mesmo que a presença dos conhecimentos exigidos pelo modelo TPACK sejam encontrados no perfil do professor de maneira plena e satisfatória, ela sempre será garantia de uma aprendizagem efetiva e significativa? E uma segunda questão: como mensurar a integração e articulação entre os conhecimentos de conteúdo, pedagógicos e tecnológicos de modo a garantir que o modelo TPACK tenha sido efetivamente contemplado? Tais questões são provocativas e conduzem à necessidade de novas investigações, dando continuidade a estudos que visam 
a melhoria da prática docente e consequentemente do ensino. No entanto, as reflexões até aqui parecem indicar que os conhecimentos exigidos pelo modelo TPACK, mesmo sendo encontrados em um docente de forma satisfatória, podem não garantir o sucesso do processo educativo se não houver a integração dos saberes, pois este sucesso requer que uma determinada situação de aprendizagem posta seja atendida, situação esta que nunca é igual a uma outra, visto que cada uma delas sempre está relacionada a um contexto particular.

Por outro lado, foi possível compreender que a abordagem CCS, por suas características e formas de condução prática tem potencial para promover a aprendizagem conforme aponta o modelo TPACK, e este por sua vez, parece carecer de considerar elementos da abordagem CCS para que a integração dos saberes que exige se realize plenamente, tais como: a consideração do contexto, a construção ativa pelo aprendiz, os significados construídos a partir dos conceitos trabalhados, a mediação do professor, dentre outros. Portanto, o emprego da abordagem CCS foi, no contexto pesquisado, uma das condições que favoreceram o modelo TPACK, uma vez que ela foi vivenciada mediante a integração dos saberes.

Quanto à amplitude educacional deste estudo, seus achados evidenciaram que a educação, sobretudo a dos anos iniciais do Ensino Fundamental, não pode esquivar-se de considerar o estudante como centro do processo, tendo sua aprendizagem e desenvolvimento como objetivo principal, afinal, é para este fim que todo o trabalho pedagógico e qualquer formação docente devem ser organizados.

\section{Referências}

ANDERSON, G. L.; HERR, K. O docente-pesquisador: a investigação-ação como uma forma válida de geração de conhecimentos. Revista Interinstitucional Artes de Educar, Rio de Janeiro, v.2, n.1, p. 4-24, fev./maio. 2016.

ANDRADE, P. F. de. Aprender por Projetos, Formar Educadores. In: VALENTE, J. A. (org.) Formação de professores para o uso da informática na Escola. Campinas: UNICAMP/NIED, 2003. p. 57-83.

BERALDO, R.M.S.; MACIEL, D. A. Competências do professor no uso das TDIC e de ambientes virtuais. Psicologia Escolar e Educacional, São Paulo, v. 20, n. 2, p. 209-217, mai./ago. 2016.

BISPO, P. P. G. O professor autor: saberes e experiências necessários na modalidade ead. In: CONGRESSO INTERNACIONAL DE EDUCAÇÃO A DISTÂNCIA, 21,. 2015, São João da Boa Vista. Texto da Biblioteca Online da ABED. São Paulo: ABED, 2015. p. 1-10. 
BOGDAN, R. C.; BIKLEN, S. K. Investigação qualitativa em educação: uma introdução à teoria e aos métodos. 12. ed. Portugal: Porto Editora, 2013.

BRASIL. Ministério da Educação. Secretaria da Educação Básica. Base Nacional Comum Curricular. Brasília-DF: MEC, 2017.

BRASIL. Ministério da Educação e Cultura/INEP. Relatório Do $3^{\circ}$ Ciclo de Monitoramento das Metas do Plano Nacional De Educação - 2020. Brasília: Instituto Nacional de Estudos e Pesquisas Educacionais Anísio Teixeira (INEP): Brasília-DF, 2020.

CAMPOS, F. R. P. Os professores como autores e editores de recursos educativos digitais: uma investigação-ação na escola. 2012. Tese (Doutorado em Educação) - Instituto de Educação, Universidade de Lisboa, Lisboa, 2012.

COLL, C; MONEREO, C. Psicologia da educação virtual: aprender e ensinar com as tecnologias da informação e da comunicação. Porto Alegre: Artmed, 2010.

CGI. Comitê Gestor da Internet no Brasil. Pesquisa sobre o uso das tecnologias da informação e comunicação nas escolas brasileiras. TIC Educação 2016. São Paulo: Comitê Gestor da Internet no Brasil, 2017. Disponível em: https://cetic.br/media/docs/publicacoes/2/TIC_EDU_2016_LivroEletronico.pdf. Acesso em: 10 de fev. de 2021.

DIAS, I. S. Competências em Educação: conceito e significado pedagógico. Revista Semestral da Associação Brasileira de Psicologia Escolar e Educacional, São Paulo. v.14, n.1, p. 73-78, jun. 2010.

GATTI, B. A. Formação de professores no Brasil: características e problemas. Educ. Soc., Campinas, v. 31, n. 113, p. 1355-1379, dez. 2010.

IMBERNÓN, F. Formação continuada de professores. Porto Alegre: Artmed, 2010.

KENSKI, V. M. Tecnologias e ensino presencial e a distância. 7. ed. Campinas: Papirus, 2003. Série Prática Pedagógica.

KOEHLER, M. J.; MISHRA, P.; CAIN, W. Qué son los Saberes Tecnológicos y Pedagógicos del Contenido (TPACK)? Virtualidad, Educación y Ciencia, Córdoba, n. 10, ano 6, p. 9-23, jun. 2015.

LEFFA, V. J. Uma ferramenta de autoria para o professor: o que é e como se faz. Letras de Hoje, Porto Alegre, v.41, n. 2, p.189 - 214, jun. 2006.

LIBANEO, J. C. Adeus professor, adeus professora? Novas exigências educacionais e profissão docente. 13. ed. São Paulo: Cortez, 2011.

LOPES, D. Q.; SOMMER, L. H.; SCHMIDT, S. Professor-propositor: a curadoria como estratégia para a docência on-line. Educação \& linguagem, São Paulo, v. 17, n. 2, p. 54-72, jul./dez. 2014.

LOPES, R. P.; FURKOTTER, M. Formação inicial de professores em tempos de TDIC: uma questão em aberto. Educação em Revista, Belo Horizonte, v. 32, n. 4, p. 269-296, dez. 2016.

MISHRA, P.; KOEHLER, M. J. Technological Pedagogical Content Knowledge: A framework for teacher knowledge. Teachers College Record, Waynesville, v. 108, n. 6, p. 1017-1054, jun. 2006. 
MORAN, J. M. Ensino e aprendizagem inovadores com tecnologias audiovisuais e telemáticas. In: MORAN, J. M.; MASETTO, M. T.; BEHRENS, M. A. Novas tecnologias e mediação pedagógica. 10. ed. Campinas: Papirus, 2006. p.11-65.

MOREIRA, M. A. Aprendizagem significativa subversiva. Série-Estudos - Periódico do Programa de Pós-Graduação em Educação da UCDB, Campo Grande, v.1, n. 21, p.15-32, jan./jun. 2006.

ROSA, M. I. F. P. S.; SCHNETZLER, R. P. A investigação-ação na formação continuada de professores de ciências. Ciência e Educação, Bauru, v. 9, n. 1, p. 27-39, 2003.

SANTOS, D. A; SCHLÜNZEN, E. T. A Construção Teórico-Metodológica Da Abordagem Construcionista, Contextualizada E Significativa. Colloquium Humanarum, Presidente Prudente, v. 12, n. Especial, p. 933-941, out. 2015.

SCHLÜNZEN, E. T. M. Mudanças nas Práticas Pedagógicas do Professor: criando um ambiente construcionista contextualizado e significativo para crianças com necessidades especiais físicas. 2000. Tese (Doutorado em Educação: Currículo) - Pontifícia Universidade Católica de São Paulo, São Paulo, 2000.

SCHLÜNZEN, E. T. M. Abordagem construcionista, contextualizada e significativa: formação, extensão e pesquisa em uma perspectiva inclusiva. 2015. Tese de Livre Docência Universidade Estadual Júlio de Mesquita Filho, Faculdade de Ciências e Tecnologia, Presidente Prudente, 2015.

SCHLÜNZEN, E. T. M., SCHLÜNZEN JÚNIOR, K.; SANTOS, D. A. N. Formação de professores, uso de tecnologias digitais de informação e comunicação e escola inclusiva: possibilidades de construção de uma abordagem de formação construcionista, contextualizada e significativa. Revista Pedagógica - UNOCHAPECó, Chapecó, v. 13, n. 26, p. 227-257, jan/jun. 2011.

SCHLÜNZEN, E. T., SANTOS, D. A. Práticas Pedagógicas do Professor: Abordagem construcionista, contextualizada e significativa para uma educação inclusiva. Curitiba: Appris, 2016.

SILVA, M. M. A. Formação continuada de professores e tecnologia: concepções docentes, possibilidades e desafios do uso das tecnologias digitais na educação básica. 2014. Dissertação (Mestrado em Educação Matemática e Tecnológica) - Centro de educação, Universidade Federal de Pernambuco, Recife, 2014.

SOUSA, S. O.; SCHLÜNZEN JUNIOR, K. Blended Learning: reflexões sobre os atributos de uma aprendizagem mista. Tecnologias de Informação e Comunicação - Perspetivas e Desafios. Santarém, v. 14, n. 47, p. 98-121, jun. 2018.

SOUSA, S. O.; TERÇARIOL, A. A. L.; GITAHY, R. R. C. Conhecimento tecnológico pedagógico do conteúdo: construção de conceitos e habilidades didáticas. Perspectiva, Florianópolis, v. 35, n. 4, p. 1215-1239, out.dez. 2017.

TARDIF, M. Saberes docentes e formação profissional. 5. ed. Petrópolis, RJ: Vozes, 2002.

TAROUCO, L. M. R. Competências digitais dos professores. In: COMITÊ GESTOR DA INTERNET NO BRASIL. TIC Educação 2018. São Paulo: CGI.br, 2019. p. 33-44. 
VEEN, W.; VRAKKING, B. Homo Zappiens: educando na era digital. Trad. de Vinícius Figueira. Porto Alegre: Artmed, 2009.

Recebido em: 23 de janeiro de 2021.

Aceito em: 04 de março de 2021. 